\title{
Cardiac Manifestations of Multisystem Inflammatory Syndrome in Children (MIS-C) Following COVID-19
}

\author{
Eveline Y. $\mathrm{Wu}^{1,2} \cdot \mathrm{M}$. Jay Campbell ${ }^{3,4}$ \\ Accepted: 18 August 2021 / Published online: 1 October 2021 \\ (c) The Author(s), under exclusive licence to Springer Science+Business Media, LLC, part of Springer Nature 2021
}

\begin{abstract}
Purpose of Review To review the spectrum of cardiac manifestations and treatments of multisystem inflammatory syndrome in children (MIS-C) associated with coronavirus disease 2019 (COVID-19).

Recent Findings Studies demonstrate that up to $80 \%$ of children with MIS-C may have cardiac involvement on a spectrum of severity. Cardiac manifestations include myocarditis, coronary artery aneurysms, conduction abnormalities, and arrhythmias. Current treatments, including inotropic support, immunomodulatory therapy, and anti-coagulation, have been effective at resolving these cardiac findings in the majority of patients. COVID-19 can also cause myocarditis in the acute stage of illness and recent descriptions of COVID-19 vaccine myocarditis have occurred.

Summary Cardiac manifestations are common in MIS-C and should be assessed for at presentation and during the clinical course as indicated.
\end{abstract}

Keywords COVID-19 $\cdot$ Multisystem inflammatory syndrome in children (MIS-C) · Cardiac $\cdot$ Myocarditis · Coronary artery aneurysms · Arrhythmia

\section{Introduction}

In December 2019, the coronavirus disease 2019 (COVID19) due to the severe acute respiratory syndrome coronavirus 2 (SARS-CoV-2) first emerged in Wuhan, China [1,2]. By March 2020, the World Health Organization (WHO) declared COVID-19 a global pandemic [3]. Initial reports

This article is part of the Topical Collection on Congenital Heart Disease.

M. Jay Campbell

michael.campbell2@duke.edu

Eveline Y. Wu

eveline.wu@unc.edu

1 Division of Pediatric Rheumatology, The University of North Carolina at Chapel Hill, 030 MacNider Hall, CB \#7231, Chapel Hill, NC 27599, USA

2 Division of Pediatric Allergy/Immunology, The University of North Carolina at Chapel Hill, Chapel Hill, NC, USA

3 Division of Pediatric Cardiology, Duke University Medical Center, 2301 Erwin Road, Children's Health Center 1st Floor, Room 1921, Durham, NC 27710, USA

4 Duke Cardiovascular Magnetic Resonance Center, Durham, NC, USA from Wuhan, China, suggested that children were largely spared or presented with milder symptoms compared to adult counterparts [4, 5]. By late April 2020, however, there were reports from COVID-19 epicenters across Europe describing clusters of children being hospitalized with a severe Kawasaki-like disease and hyperinflammatory shock syndrome [6•, 7•]. On May 6, 2020, the Department of Health for New York State, a COVID-19 epicenter in the USA, released a health advisory informing on 64 children hospitalized with a multisystem inflammatory syndrome potentially associated with COVID-19 [8]. On May 14, 2020, the Centers for Disease Control (CDC) issued a Health Alert Network advisory providing a case definition and summary of manifestations for what was ultimately termed multisystem inflammatory syndrome in children (MIS-C) associated with COVID-19 [9].

MIS-C is defined as (1) a person $<21$ years presenting with fever, laboratory evidence of inflammation, and evidence of clinically severe illness requiring hospitalization with multisystem organ involvement; (2) in the absence of alternative diagnoses; and (3) with a temporal association with COVID-19 demonstrated by a positive current or recent SARS-CoV-2 reverse transcription-polymerase chain reaction (RT-PCR), serology, or antigen test or known 
COVID-19 exposure within the 4 weeks prior to symptom onset (Table 1) [9]. Multiorgan dysfunction is a cardinal feature of MIS-C, and prominent cardiovascular complications, particularly myocardial and coronary artery involvement, were recognized early. This article first provides an overview of MIS-C associated with COVID-19 followed by a detailed discussion on the spectrum of cardiac manifestations and outcomes.

\section{Multisystem Inflammatory Syndrome in Children}

As of June 2, 2021, the CDC has received reports of over 4000 MIS-C cases in the USA [10]. The current estimated incidence of MIS-C is 2 per 100,000 persons younger than 21 years old. This is in comparison to SARS-CoV-2 infection with an estimated incidence of 322 per 100,000 persons younger than 21 years old $[11,12]$. Overall, MIS-C remains a rare, but serious, presentation of COVID-19 in children.

Among the largest case series of 539 MIS-C patients from the overcoming COVID-19 network, a larger proportion of children were diagnosed between 6 and 12 years of age with an average age of 8.9 years [13••]. Approximately $60 \%$ of the cohort was male. A notable observation across many studies is that a majority of children with MIS-C are of Black race or Hispanic ethnicity. A recent systematic review found that $31-62 \%$ of persons with MIS-C were of Black or Afro-Caribbean race and 36-39\% were Hispanic or Latino [14]. Even after accounting for the increased burden of COVID-19, the incidence of MIS-C is higher among Black and Hispanic or Latino persons compared to White persons [15].

The risk factors that predispose some children to develop MIS-C and the underlying immunopathology are still not yet fully understood. MIS-C occurs 2-4 weeks after SARSCoV2 infection and most patients have positive IgG antibody responses, suggesting a post-viral inflammatory reaction. Among children with acute, treatment-naïve MIS-C, the hyperinflammatory response is characterized by elevated levels of cytokines including interleukin (IL)-1 $\beta$, IL-6, IL-8, IL-10, IL-17, tumor necrosis factor $\alpha$ (TNF- $\alpha)$, interferon- $\gamma$ (IFN- $\gamma$ ), and IL-2 receptor antagonist [16]. Neutrophils and macrophages demonstrate an activated phenotype with increased surface expression of Fc $\gamma \mathrm{R} 1[16,17]$. The hyperinflammatory response is also associated with endothelial dysfunction and microangiopathy. Patients with MIS-C have elevated biomarkers associated with vascular inflammation and damage [18]. Consistent with a microangiopathy, schistocytes and Burr cells are often present on peripheral smear [19]. MIS-C patients also have high levels of soluble C5b-9 (sC5b-9), an activation product of the terminal complement cascade that has been associated with microangiopathy in other disease states $[19,20]$. These immunologic

Table 1 Multisystem inflammatory syndrome in children (MIS-C) associated with coronavirus disease 2019 (COVID-19)

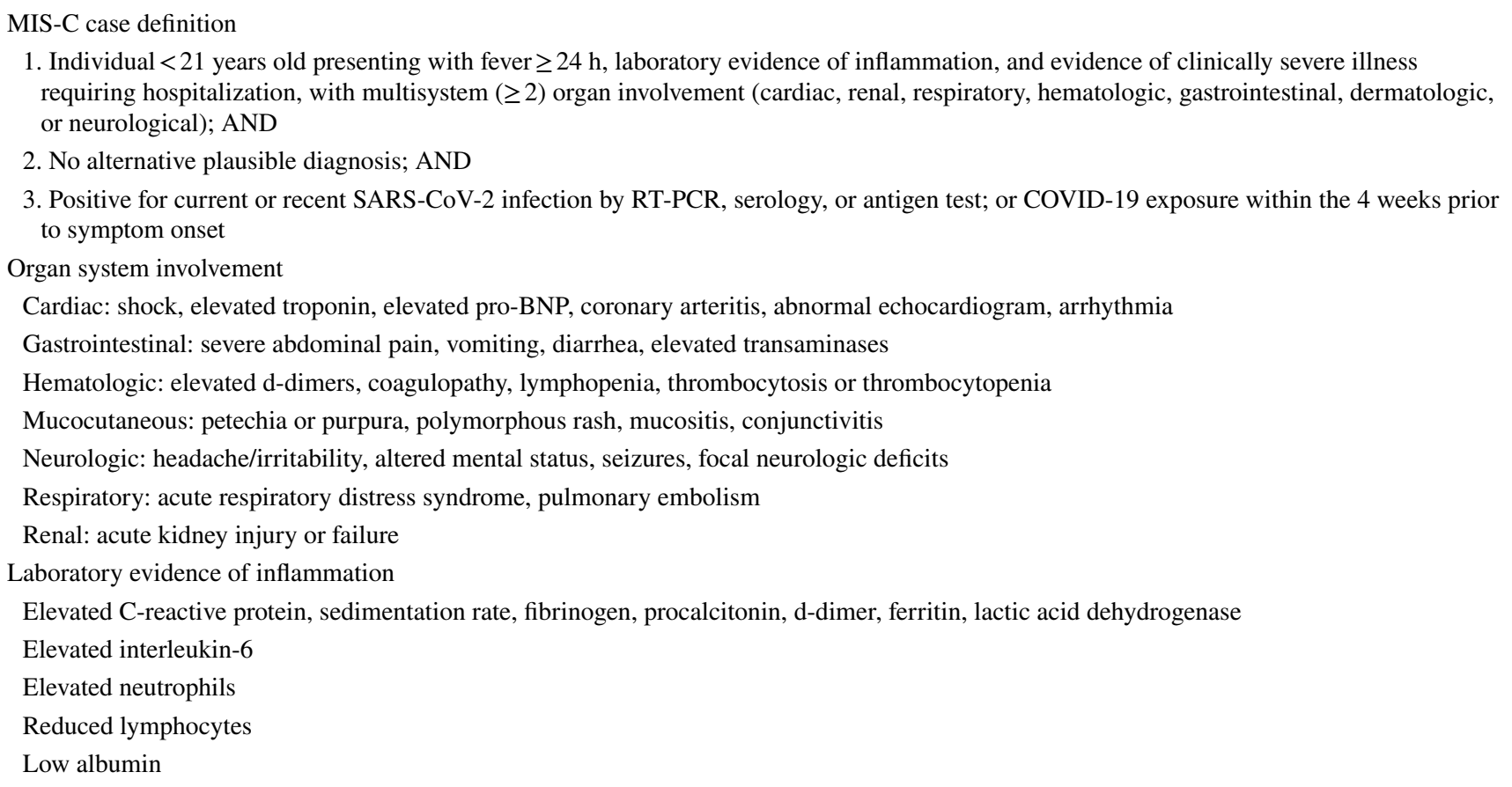

$B N P$ brain natriuretic peptide; $R T$ - $P C R$ reverse transcription-polymerase chain reaction; $S A R S-C o V-2$ severe acute respiratory syndrome coronavirus 2. (Adapted from [9]) 
disturbances do appear to resolve following illness recovery [16].

Children with MIS-C can present with a diverse spectrum of symptoms and severity. Following the key criteria of fever, gastrointestinal symptoms, including abdominal pain, vomiting, and/or diarrhea, are the most common manifestations and present in $70-90 \%$ of patients [13••, 21]. Other manifestations include rash (52-60\%), conjunctivitis $(45-56 \%)$, oral mucosal changes $(27-42 \%)$, peripheral edema (9-37\%), headache (29\%), and altered mental status or confusion (2-9\%) [11, 22, 23]. Hematologic abnormalities occur in approximately $80 \%$ of MIS-C patients and the most common are lymphopenia, neutrophilia, thrombocytopenia, and anemia $[11,22]$. Other characteristic laboratory findings include hyponatremia; hypoalbuminemia; increased transaminases; elevated D-dimer; and elevated inflammatory markers including C-reactive protein, sedimentation rate, and ferritin $[11,22]$. Up to $50 \%$ of children with MIS-C can present with shock and approximately $50-80 \%$ have critical illness requiring intensive care during their course [11, 22, 23]. Cardiac manifestations are discussed further below.

\section{Cardiac Findings OF MIS-C}

Cardiac involvement occurs in up to $67-80 \%$ of children with MIS-C and is more common in MIS-C than Kawasaki

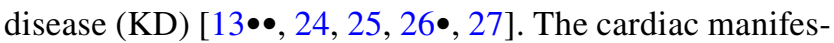
tations include ventricular dysfunction, coronary artery aneurysms, conduction abnormalities, and arrhythmias. The cardiac clinical presentation of MIS-C can occur along a spectrum of disease severity. Many patients present with cardiovascular compromise and shock that can be quite severe and sudden [21, 26•, 28••]. On the opposite end of the spectrum, patients may present with no cardiovascular involvement. When MIS-C is suspected, a thorough cardiac evaluation including troponin and brain natriuretic peptide (BNP) levels, electrocardiogram (ECG), and transthoracic echocardiogram should be urgently obtained. Additional cardiac testing such as a cardiac MRI (CMR) or computed tomography (CT) of the chest may also be obtained as indicated.

\section{Coronary Artery Abnormalities}

The initial reports of MIS-C described a KD-like illness $[6 \bullet, 7 \bullet]$. There is an increasing appreciation that MIS-C is distinct from $\mathrm{KD}$, but the disorders share some clinical features including coronary artery dilation [7•]. The prevalence of coronary artery aneurysms in the setting of MIS-C

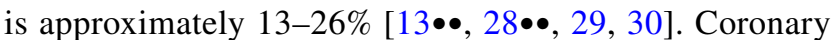
artery abnormalities are more common in male patients and in those with mucocutaneous and conjunctival involvement
[31]. The coronary artery dilation is most often mild with rarer descriptions of more severe coronary artery dilation $[7 \bullet, 32]$. Some reports describe echogenicity of the coronary arteries on echocardiography; however, this is a subjective finding and difficult to standardize [33].

The etiology of coronary artery dilation is unclear. Coronary artery dilation could be secondary to a vasculitis or generalized hyperinflammation. Outcomes with regard to coronary artery dilation and aneurysms in MIS-C have been favorable with many coronary artery abnormalities normal-

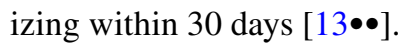

\section{Ventricular Dysfunction}

Ventricular dysfunction is a common finding of MIS-C with

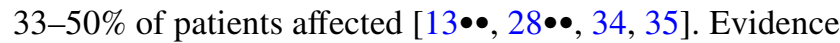
for this includes elevated BNP levels and abnormalities of ventricular function on echocardiography and/or CMR [34, $36,37]$. The mechanism for the change in ventricular function appears to be multifactorial. In some cases, elevated cardiac enzymes are present and indicate cardiomyocyte injury


In other cases, ventricular function is decreased but cardiac enzymes are normal, suggesting an alternate pathogenesis such as generalized inflammation or changes in loading conditions. Autopsy studies on MIS-C patients are limited but have indicated inflammation of the endocardium, myocardium, and pericardium as well as contraction band necrosis [38, 39]. SARS-CoV-2 virus within myocardial tissue has also been reported [39]. Fortunately, and similar to the immunologic disturbances noted during the acute phase of illness, the ventricular dysfunction also normalizes over time $[13 \bullet \bullet, 35]$.

Echocardiographic findings indicate evidence of systolic and diastolic dysfunction [40]. A reduction in left ventricular ejection fraction is the most commonly reported finding,

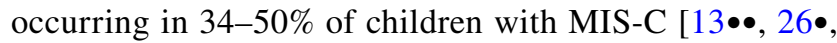
28••, 34, 37, 40, 41]. Echocardiographic strain studies have indicated abnormal ventricular strain [36, 37, 40-42]. In some cohorts, lower strain values are more frequent than a reduction in left ventricular ejection fraction and can be seen in patients with a normal left ventricular ejection fraction [37]. Decreased strain values are predictive of worse clinical outcomes [36, 37]. Two studies reported frequent reductions of longitudinal strain, while another reported a pattern of abnormal circumferential strain with preserved longitudinal strain [36, 37, 42]. Abnormalities of diastolic dysfunction as measured by spectral and tissue Doppler and strain have also been noted [40, 41]. Evidence of diastolic dysfunction also persists after normalization of left ventricular ejection fraction [40]. 
The investigation of acute MIS-C patients by CMR is limited because of clinical instability and the need for anesthesia in younger children. One study of 3 acute MIS-C patients revealed abnormalities of $\mathrm{T} 1$ and $\mathrm{T} 2$. These patients had repeat scans 14 days after discharge and previously abnormal T1/T2 values normalized. In this study, there were no findings of hyperenhancement by late gadolinium enhancement imaging [25]. Several studies have evaluated MIS-C patients by CMR after the acute illness ( $2-8$ weeks after illness) [25, 28••, 34, 41, 43]. Strain abnormalities have been noted by CMR and were seen most commonly in patients with reduced left ventricular ejection fraction [41]. Areas of hyperenhancement are uncommon on late gadolinium enhancement, occurring in $0-14 \%$ of patients scanned (Fig. 1) [28••, 34, 41, 43]. Abnormalities of T2 and T1 have been noted in $0-33 \%$ and $0-5 \%$ of MIS-C patients, respectively [28••, 34, 41, 43]. Positron emission tomography (PET)/CT was also used in one patient and demonstrated evidence of acute inflammation that resolved on a later scan [44].

\section{Conduction Abnormalities and Arrhythmias}

Arrhythmias and conduction abnormalities are frequent with ECG findings occurring in 28-67\% of MIS-C patients [45•, 46, 47]. The most common are low QRS amplitude and T-wave abnormalities [46]. All ECG intervals have been observed to be prolonged with the PR interval being most frequently affected [46]. First-degree heart block is common occurring in $6.3-25 \%$ of MIS-C patients [28••, 46, 48]. The finding of first-degree heart block has not been associated with elevated cardiac enzymes $[48,49]$. Second- or third-degree heart block has been detected in 7\% of MIS-C patients [48]. Patients with second- or third-degree heart block had ventricular dysfunction and elevated BNP levels but normal troponin levels [48]. QT prolongation and QRS prolongation can also occur with reported frequencies of

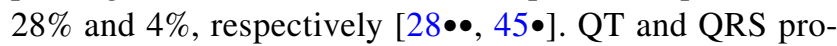
longation more rapidly resolve than PR prolongation [46]. Sinus bradycardia is also an observed finding $[46,50,51]$. Cases of severe sinus bradycardia have resolved following anti-inflammatory therapy. Reports on ST changes have been discrepant with some reporting this as a rare finding and others indicating this is a more common finding [46, 47]. Tachyarrhythmia has also been noted [46, 52-54].

\section{Management OF MIS-C}

MIS-C management includes supportive care and immunomodulatory therapy (Table 2). Guidance statements on the management of MIS-C endorsed by the American College of Rheumatology have been published [55, 56]. Patients with MIS-C are often hemodynamically unstable and require

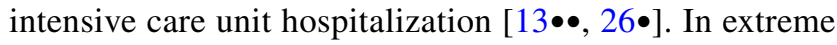
cases, extracorporeal membranous oxygenation (ECMO)
Fig. 1 Segmented late gadolinium cardiac MRI image illustrating mid-myocardial hyperenhancement (yellow arrows) consistent with myocarditis in a pediatric patient with MIS-C

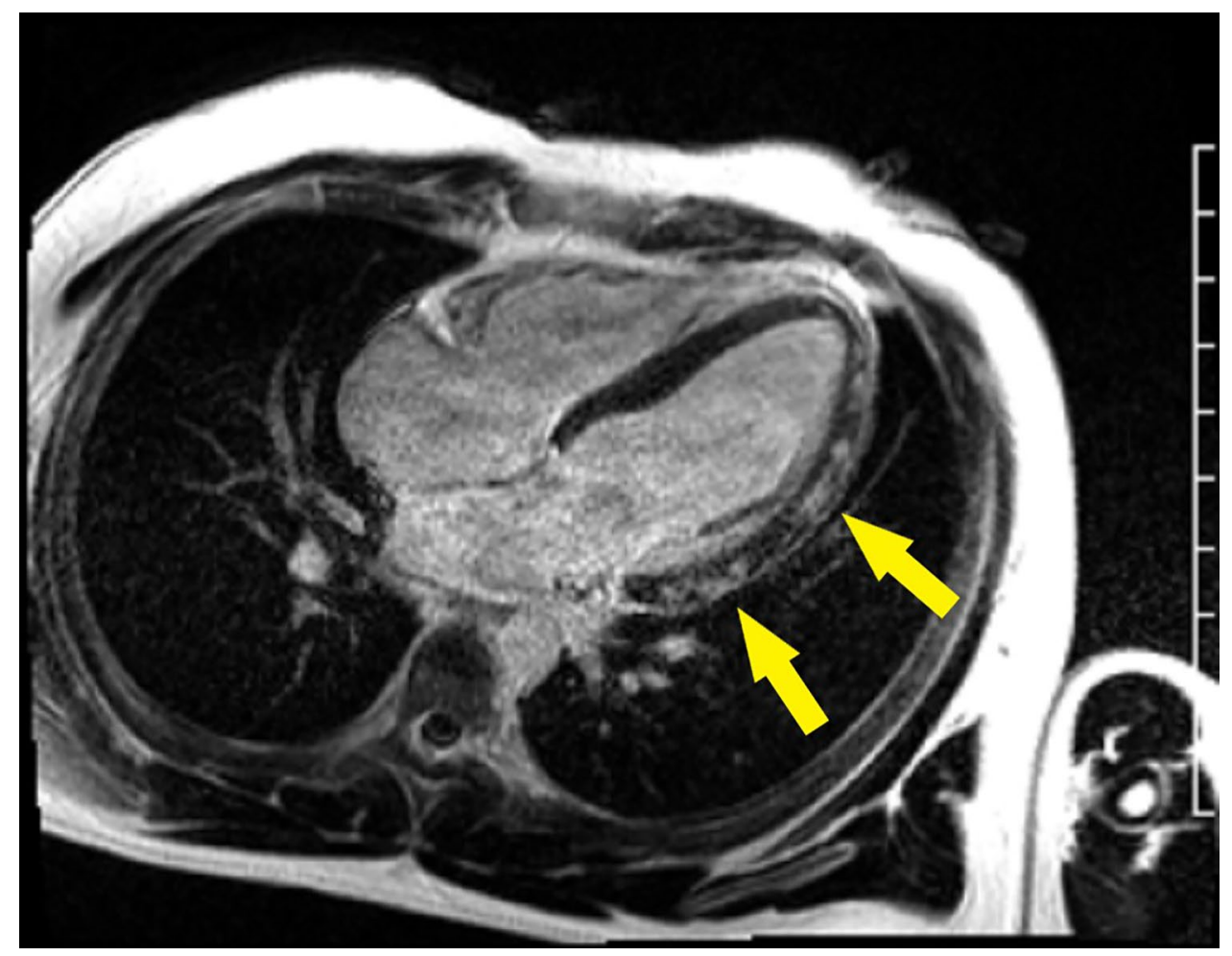


Table 2 Immunomodulatory treatment of multisystem inflammatory syndrome in children (MIS-C)

\begin{tabular}{|c|c|c|}
\hline Agent & Dosing and regimen & Special considerations \\
\hline IVIG & $\begin{array}{l}2 \mathrm{gm} / \mathrm{kg} / \mathrm{dose} \\
\text { Maximum } 70-100 \mathrm{~g} / \mathrm{dose}\end{array}$ & $\begin{array}{l}\text { IVIG dosing is based on ideal body weight } \\
\text { In patients with cardiac dysfunction, IVIG may be given in divided doses of } 1 \mathrm{gm} / \mathrm{kg} \\
\text { daily over } 2 \text { days }\end{array}$ \\
\hline $\begin{array}{l}\text { Glucocorticoids } \\
\text { Prednisone } \\
\text { Prednisolone } \\
\text { Methylprednisolone }\end{array}$ & $\begin{array}{l}\text { Mild disease: } 1-2 \mathrm{mg} / \mathrm{kg} / \mathrm{day} \\
\text { Moderate disease: } 10 \mathrm{mg} / \mathrm{kg} / \mathrm{day} \\
\text { Severe disease: } 30 \mathrm{mg} / \mathrm{kg} / \text { day } \\
\text { Maximum } 1000 \mathrm{mg} / \mathrm{dose}\end{array}$ & $\begin{array}{l}\text { Add low-to-moderate dose glucocorticoids to IVIG for patients with shock and/or } \\
\text { organ-threatening disease } \\
\text { Add high-dose, IV glucocorticoids for patients refractory to IVIG and low-to-moderate } \\
\text { dose glucocorticoids and/or requiring multiple inotropes and/or vasopressors }\end{array}$ \\
\hline Anakinra & $>4 \mathrm{mg} / \mathrm{kg} /$ day IV or SC & $\begin{array}{l}\text { Consider in patients with disease refractory to IVIG and glucocorticoids, features of } \\
\text { macrophage activation syndrome, shock requiring multiple inotropes and/or vaso- } \\
\text { pressors, and/or contraindications to long-term use of glucocorticoids }\end{array}$ \\
\hline Tocilizumab & $\begin{array}{l}<30 \mathrm{~kg}, 12 \mathrm{mg} / \mathrm{kg} / \text { dose IV } \\
\geq 30 \mathrm{~kg}, 8 \mathrm{mg} / \mathrm{kg} / \text { dose IV } \\
\text { Maximum } 800 \mathrm{mg} / \text { dose }\end{array}$ & $\begin{array}{l}\text { Limited evidence for use based largely on case reports and case series. Considerations } \\
\text { for use are similar to anakinra and availability may vary across centers }\end{array}$ \\
\hline
\end{tabular}

Adapted from $[55,56]$

$I V$ intravenous; IVIG intravenous immunoglobulin; $S C$ subcutaneous

may be required with rates reported as $4.4 \%$ [21, 57]. MIS-C mortality rates are $1.7-2 \%[21,26 \bullet, 27]$.

Initial treatment of MIS-C cardiac complications is focused on patient stabilization. In the patient with poor cardiac output, mechanical ventilation and inotropic support may be needed [21, 26•]. Arrhythmias should be treated accordingly. After or in parallel with the initial stabilization process, management includes treating the underlying inflammation, reducing coronary artery dilation, and minimizing risks for intra-cardiac or coronary artery thrombi.

A stepwise approach to immunomodulatory treatment is recommended, with intravenous immunoglobulin (IVIG) and/or corticosteroids considered as first-line agents (Table 2). Among 518 MIS-C patients who received immunomodulatory therapies during the course of their illness, a majority received IVIG in addition to glucocorticoids (47\%) followed by IVIG, glucocorticoids, and a biologic (21\%) and IVIG alone (17\%) [26•]. Anakinra, an IL-1 receptor antagonist, and tocilizumab, a monoclonal antibody directed against the IL-6 receptor, are the most common biologic therapies used [21, 22]. Recent evidence is mixed regarding the effects of immunomodulatory therapy on cardiac outcomes. One study showed that initial therapy with a combination of IVIG and corticosteroids is superior at reducing cardiovascular dysfunction and vasodilatory shock, while a second study revealed no difference in initial therapies on cardiovascular outcomes [26•, 58•].

Thrombotic complications are common with MIS-C, and patients with thrombotic complications have higher mortality [59]. In patients with greater than mild to moderate levels of depressed ventricular function, anti-coagulation with heparin, enoxaparin, warfarin, and/or anti-platelet agents should be considered to prevent intra-cardiac thrombi and subsequent embolic events [60]. Patients with giant coronary artery aneurysms also require aggressive anti-coagulation, initially with heparin or enoxaparin with subsequent later conversion to a regimen of warfarin and anti-platelet agents [61]. The treatment of coronary artery ectasia and aneurysms has been adapted from the standard treatment of KD [61-63]. The prescribed cardiac imaging and stress testing follow-up for coronary artery dilation has also been adapted from KD protocols [61, 63].

\section{COVID-19 Myocarditis}

Myocarditis is a known complication of acute COVID-19 infection in adults [64-69]. Initial reports from Wuhan, China, noted elevated troponin levels in infected patients [70, 71]. CMR studies also described a high incidence of CMR myocardial abnormalities such as T1, T2, and late gadolinium enhancement $[66,67]$. The high incidence of abnormal CMR findings is discrepant to autopsy studies that examined patients who died from COVID-19 and report a myocarditis prevalence of only $1-2 \%$ [64, 65, 72]. These discrepancies are still being investigated as the cardiology community attempts to better understand the cardiovascular effects of acute COVID-19 infection.

Possible etiologies for the myocardial damage caused by COVID-19 include direct viral injury to the myocardium and myocardial damage as a result of the hyperinflammatory state $[65,72,73]$.

Myocarditis associated with acute COVID-19 infection has also been seen in pediatric patients $[74,75]$. Children with COVID-19 myocarditis, compared to non-COVID-19 myocarditis, have higher C-reactive protein levels, variable clinical presentations, shorter duration of need for inotropes, and a shorter time for recovery of left ventricular systolic function [74]. The cardiac status of children and young adult athletes with a history of COVID-19 infection has been an 
area of specific interest. CMR studies of competitive athletes have shown a high prevalence of hyperenhancement on late gadolinium enhancement and abnormal T1/T2 values, even in the setting of a history of mild COVID-19 disease [68, $69,76]$. The clinical implications of these findings and their importance in the risk stratification of a return to competitive athletics have yet to be determined.

As vaccination for COVID-19 has become more available, cases of myocarditis following vaccination have been reported in both adult and pediatric patients [77, 78]. Myocarditis following vaccination is rare but has been previously described with smallpox and influenza vaccinations [79-81]. The causal relationship of COVID-19 vaccination to these myocarditis cases has yet to be defined. The pathophysiology also needs further investigation, and this is an ongoing, rapidly evolving area of study.

\section{Conclusion}

MIS-C associated with COVID-19 is a serious, potentially life-threatening illness. Cardiac manifestations are common and occur on a spectrum of severity. Cardiac pathology includes coronary artery dilation, ventricular dysfunction, conduction abnormalities, and arrhythmias. Current treatment strategies have proven effective at resolving many of these cardiac findings, but there is still room for improvement. Close disease surveillance is ongoing and will further characterize the cardiac manifestations and potential sequelae of MIS-C. Multi-center collaborations and harmonized registries are key to understanding the natural history, refining diagnostic criteria, developing risk stratification algorithms, and determining best management.

\section{Declarations}

Conflict of Interest All authors declare no conflict of interest.

Human and Animal Rights and Informed Consent This article does not contain any data with human or animal subjects performed by any of the authors.

\section{References}

Papers of particular interest, published recently, have been highlighted as:

- Of importance

$\bullet$ Of major importance

1. Zhu N, Zhang D, Wang W, Li X, Yang B, Song J, et al. A novel coronavirus from patients with pneumonia in China, 2019. N Engl J Med. 2020;382(8):727-33.
2. Huang C, Wang Y, Li X, Ren L, Zhao J, Hu Y, et al. Clinical features of patients infected with 2019 novel coronavirus in Wuhan, China. Lancet. 2020;395(10223):497-506.

3. Cucinotta D, Vanelli M. WHO declares COVID-19 a pandemic. Acta Biomed. 2020;91(1):157-60.

4. Lu X, Zhang L, Du H, Zhang J, Li YY, Qu J, et al. SARS-CoV-2 infection in children. N Engl J Med. 2020;382(17):1663-5.

5. Dong Y, Mo X, Hu Y, Qi X, Jiang F, Jiang Z, et al. Epidemiology of COVID-19 among children in China. Pediatrics. 2020;145(6):e20200702.

6. Riphagen S, Gomez X, Gonzalez-Martinez C, Wilkinson N, Theocharis P. Hyperinflammatory shock in children during COVID-19 pandemic. Lancet. 2020;395(10237):1607-8. One of the first reports of children being hospitalized with shock and a hyperinflammatory syndrome possibly related to SARS-CoV-2.

7. Verdoni L, Mazza A, Gervasoni A, Martelli L, Ruggeri M, Ciuffreda M, et al. An outbreak of severe Kawasaki-like disease at the Italian epicentre of the SARS-CoV-2 epidemic: an observational cohort study. Lancet. 2020;395(10239):1771-8. One of the first reports of children being hospitalized with a Kawasaki disease-like illness possibly related to SARS-CoV-2.

8. New York State Department of Health Bureau of Communicable Disease Control. Health advisory: pediatric multi-system inflammatory syndrome potentially associated with coronavirus disease (COVID19) in children. https://www.health.ny.gov/press/releases/2020/docs/ 2020-05-06_covid19_pediatric_inflammatory_syndrome.pdf.

9. Centers for Disease Control and Prevention. Multisystem inflammatory syndrome in children (MIS-C) associated with coronavirus disease 2019 (COVID-19). https://emergency.cdc.gov/han/ 2020/han00432.asp.

10. Health Department-Reported Cases of Multisystem Inflammatory Syndrome in Children (MIS-C) in the United States. https:// www.cdc.gov/mis-c/cases/index.html.

11. Dufort EM, Koumans EH, Chow EJ, Rosenthal EM, Muse A, Rowlands J, et al. Multisystem inflammatory syndrome in children in New York state. N Engl J Med. 2020;383(4):347-58.

12. Levin M. Childhood multisystem inflammatory syndrome-a new challenge in the pandemic. N Engl J Med. 2020;383(4):393-5.

13.• Feldstein LR, Tenforde MW, Friedman KG, Newhams M, Rose EB, Dapul H, et al. Characteristics and outcomes of US children and adolescents with multisystem inflammatory syndrome in children (MIS-C) compared with severe acute COVID-19. JAMA. 2021;325(11):1074-87. This report is currently the largest case series including 539 children with MIS-C from the Overcoming COVID-19 surveillance registry. The study observed that most cardiovascular involvement resolved over time.

14. Abrams JY, Godfred-Cato SE, Oster ME, Chow EJ, Koumans $\mathrm{EH}$, Bryant B, et al. Multisystem inflammatory syndrome in children associated with severe acute respiratory syndrome coronavirus 2: a systematic review. J Pediatr. 2020;226:45-54.e1.

15. Payne AB, Gilani Z, Godfred-Cato S, Belay ED, Feldstein LR, Patel MM, et al. Incidence of multisystem inflammatory syndrome in children among US persons infected with SARSCoV-2. JAMA Netw Open. 2021;4(6):e2116420.

16. Carter MJ, Fish M, Jennings A, Doores KJ, Wellman P, Seow $\mathrm{J}$, et al. Peripheral immunophenotypes in children with multisystem inflammatory syndrome associated with SARS-CoV-2 infection. Nat Med. 2020;26(11):1701-7.

17. Gruber CN, Patel RS, Trachtman R, Lepow L, Amanat F, Krammer $\mathrm{F}$, et al. Mapping systemic inflammation and antibody responses in multisystem inflammatory syndrome in children (MIS-C). Cell. 2020;183(4):982-95.e14.

18. Consiglio CR, Cotugno N, Sardh F, Pou C, Amodio D, Rodriguez $\mathrm{L}$, et al. The immunology of multisystem inflammatory syndrome in children with COVID-19. Cell. 2020;183(4):968-81.e7. 
19. Diorio C, Henrickson SE, Vella LA, McNerney KO, Chase J, Burudpakdee $\mathrm{C}$, et al. Multisystem inflammatory syndrome in children and COVID-19 are distinct presentations of SARSCoV-2. J Clin Invest. 2020;130(11):5967-75.

20. Diorio C, McNerney KO, Lambert M, Paessler M, Anderson EM, Henrickson SE, et al. Evidence of thrombotic microangiopathy in children with SARS-CoV-2 across the spectrum of clinical presentations. Blood Adv. 2020;4(23):6051-63.

21. Ahmed M, Advani S, Moreira A, Zoretic S, Martinez J, Chorath $\mathrm{K}$, et al. Multisystem inflammatory syndrome in children: a systematic review. EClinicalMedicine. 2020;26:100527.

22. Feldstein LR, Rose EB, Horwitz SM, Collins JP, Newhams MM, Son MBF, et al. Multisystem inflammatory syndrome in U.S. children and adolescents. N Engl J Med. 2020;383(4):334-46.

23. Whittaker E, Bamford A, Kenny J, Kaforou M, Jones CE, Shah $\mathrm{P}$, et al. Clinical characteristics of 58 children with a pediatric inflammatory multisystem syndrome temporally associated with SARS-CoV-2. JAMA. 2020;324(3):259-69.

24. Zhang QY, Xu BW, Du JB. Similarities and differences between multiple inflammatory syndrome in children associated with COVID-19 and Kawasaki disease: clinical presentations, diagnosis, and treatment. World J Pediatr. 2021;17(4):335-40.

25. Blondiaux E, Parisot P, Redheuil A, Tzaroukian L, Levy Y, Sileo C, et al. Cardiac MRI in children with multisystem inflammatory syndrome associated with COVID-19. Radiology. 2020;297(3):E283-8.

26. Son MBF, Murray N, Friedman K, Young CC, Newhams MM, Feldstein LR, et al. Multisystem inflammatory syndrome in children-initial therapy and outcomes. N Engl J Med. 2021 Jul 1;385(1)23-34. This study looked at 518 MIS-C patients from the Overcoming COVID-19 surveillance registry and found that initial treatment with IVIG plus corticosteroids was associated with lower risk of cardiovascular dysfunction than IVIG alone.

27. Hoste L, Van Paemel R, Haerynck F. Multisystem inflammatory syndrome in children related to COVID-19: a systematic review. Eur J Pediatr. 2021;180(7):2019-34.

28.• Valverde I, Singh Y, Sanchez-de-Toledo J, Theocharis P, Chikermane A, Di Filippo S, et al. Acute cardiovascular manifestations in 286 children with multisystem inflammatory syndrome associated with COVID-19 infection in Europe. Circulation. 2021;143(1):21-32. This document is the largest case series focused on detailing the cardiovascular manifestations of 286 children with MIS-C.

29. Alsaied T, Aboulhosn JA, Cotts TB, Daniels CJ, Etheridge SP, Feltes TF, et al. Coronavirus disease 2019 (COVID-19) pandemic implications in pediatric and adult congenital heart disease. J Am Heart Assoc. 2020;9(12):e017224

30. Toubiana J, Levy C, Allali S, Jung C, Leruez-Ville M, Varon E, et al. Association between SARS-CoV-2 infection and Kawasaki-like multisystem inflammatory syndrome: a retrospective matched case-control study, Paris, France, April to May 2020. Euro Surveill. 2020;25(48). https://doi.org/10.2807/1560-7917. ES.2020.25.48.2001813.

31. Abrams JY, Oster ME, Godfred-Cato SE, Bryant B, Datta SD, Campbell AP, et al. Factors linked to severe outcomes in multisystem inflammatory syndrome in children (MIS-C) in the USA: a retrospective surveillance study. Lancet Child Adolesc Health. 2021;5(5):323-31.

32. Wacker J, Malaspinas I, Vallée JP, Beghetti M. Regression of coronary arteries aneurysms 6 months after multisystem inflammatory syndrome in children (MIS-C). Eur Heart J. 2021;42(28):2803.

33. Davies P, Evans C, Kanthimathinathan HK, Lillie J, Brierley J, Waters $\mathrm{G}$, et al. Intensive care admissions of children with paediatric inflammatory multisystem syndrome temporally associated with SARS-CoV-2 (PIMS-TS) in the UK: a multicentre observational study. Lancet Child Adolesc Health. 2020;4(9):669-77.
34. Bermejo IA, Bautista-Rodriguez C, Fraisse A, Voges I, Gatehouse $\mathrm{P}$, Kang H, et al. Short-term sequelae of multisystem inflammatory syndrome in children assessed by CMR. JACC Cardiovasc Imaging. 2021;14(8):1666-7.

35. Penner J, Abdel-Mannan O, Grant K, Maillard S, Kucera F, Hassell J, et al. 6-month multidisciplinary follow-up and outcomes of patients with paediatric inflammatory multisystem syndrome (PIMS-TS) at a UK tertiary paediatric hospital: a retrospective cohort study. Lancet Child Adolesc Health. 2021. https://doi.org/10.1016/S23524642(21)00138-3.

36. Sanil Y, Misra A, Safa R, Blake JM, Eddine AC, Balakrishnan P, et al. Echocardiographic indicators associated with adverse clinical course and cardiac sequelae in multisystem inflammatory syndrome in children with COVID-19. J Am Soc Echocardiogr. 2021. https://doi.org/10.1016/j.echo.2021.04.018.

37. Kobayashi R, Dionne A, Ferraro A, Harrild D, Newburger J, VanderPluym C, et al. Detailed assessment of left ventricular function in multisystem inflammatory syndrome in children using strain analysis. CJC Open. 2021. https://doi.org/10.1016/j. cjco.2021.02.012.

38. Duarte-Neto AN, Caldini EG, Gomes-Gouvêa MS, Kanamura CT, de Almeida Monteiro RA, Ferranti JF, et al. An autopsy study of the spectrum of severe COVID-19 in children: from SARS to different phenotypes of MIS-C. EClinicalMedicine. 2021;35:100850.

39. Dolhnikoff M, Ferreira Ferranti J, de Almeida Monteiro RA, Duarte-Neto AN, Soares Gomes-Gouvêa M, Viu Degaspare N, et al. SARS-CoV-2 in cardiac tissue of a child with COVID19-related multisystem inflammatory syndrome. Lancet Child Adolesc Health. 2020;4(10):790-4.

40. Matsubara D, Kauffman HL, Wang Y, Calderon-Anyosa R, Nadaraj $\mathrm{S}$, Elias MD, et al. Echocardiographic findings in pediatric multisystem inflammatory syndrome associated with COVID-19 in the United States. J Am Coll Cardiol. 2020;76(17):1947-61.

41. Theocharis P, Wong J, Pushparajah K, Mathur SK, Simpson JM, Pascall E, et al. Multimodality cardiac evaluation in children and young adults with multisystem inflammation associated with COVID-19. Eur Heart J Cardiovasc Imaging. 2020. https://doi. org/10.1093/ehjci/jeaa212.

42. Gaitonde M, Ziebell D, Kelleman MS, Cox DE, Lipinski J, Border WL, et al. COVID-19-related multisystem inflammatory syndrome in children affects left ventricular function and global strain compared with Kawasaki disease. J Am Soc Echocardiogr. 2020;33(10):1285-7.

43. Prieto LM, Toral B, LLorente A, Coca D, Blázquez-Gamero D. Cardiovascular magnetic resonance imaging in children with pediatric inflammatory multisystem syndrome temporally associated with SARS-CoV-2 and heart dysfunction. Clin Microbiol Infect. 2021;27(4):648-50.

44. Satapathy S, Kumar R, Kavanal AJ, Krishnaraju VS, Ramachandran A, Deo P, et al. COVID-19 related multisystem inflammatory syndrome in children (MIS-C): role of (18) F-FDG PET/CT to assess myocardial involvement. J Nucl Cardiol. 2021:1-2. https://doi.org/10.1007/s12350-021-02540-x.

45. Dionne A, Newburger JW. The electrocardiogram in multisystem inflammatory syndrome in children: mind your Ps and Qs. 2021 J Pediatr. 2021 Jul;234:10-11. This paper describes electrocardiogram findings in a case series of children with MIS-C.

46. Regan W, O'Byrne L, Stewart K, Miller O, Pushparajah K, Theocharis $\mathrm{P}$, et al. Electrocardiographic changes in children with multisystem inflammation associated with COVID-19: associated with coronavirus disease 2019. J Pediatr. 2021. https://doi. org/10.1016/j.jpeds.2020.12.033.

47. Haghighi Aski B, Manafi Anari A, Abolhasan Choobdar F, Zareh Mahmoudabadi R, Sakhaei M. Cardiac abnormalities due to multisystem inflammatory syndrome temporally associated 
with Covid-19 among children: a systematic review and metaanalysis. Int J Cardiol Heart Vasc. 2021;33:100764.

48. Dionne A, Mah DY, Son MBF, Lee PY, Henderson L, Baker AL, et al. Atrioventricular block in children with multisystem inflammatory syndrome. Pediatrics. 2020;146(5):e2020009704.

49. Choi NH, Fremed M, Starc T, Weller R, Cheung E, Ferris A, et al. MIS-C and cardiac conduction abnormalities. Pediatrics. 2020;146(6):e2020009738.

50. Hallberg TC, Bjorklund AR, Slusher TM, Rodgers N. Sinus bradycardia in a toddler with multisystem inflammatory syndrome in children (MIS-C) related to COVID-19. BMJ Case Rep. 2021;14(5):e242058.

51. Tomlinson LG, Cohen MI, Levorson RE, Tzeng MB. COVID-19associated multisystem inflammatory syndrome in children presenting uniquely with sinus node dysfunction in the setting of shock. Cardiol Young. 2021:1-3. https://doi.org/10.1017/S1047951121000354.

52. Man Singh J, Palting RL, Bratincsak A. Junctional tachycardia due to multisystem inflammatory syndrome in children with SARS-CoV-2 infection in a 12-year-old female. Cardiol Young. 2021:1-3. https://doi.org/10.1017/S1047951120005016.

53. Clark BC, Sanchez-de-Toledo J, Bautista-Rodriguez C, Choueiter N, Lara D, Kang H, et al. Cardiac abnormalities seen in pediatric patients during the SARS-CoV2 pandemic: an international experience. J Am Heart Assoc. 2020;9(21):e018007.

54. Tseng YS, Herron C, Garcia R, Cashen K. Sustained ventricular tachycardia in a paediatric patient with acute COVID-19 myocarditis. Cardiol Young. 2021:1-3. https://doi.org/10.1017/ S1047951121000792.

55. Henderson LA, Canna SW, Friedman KG, Gorelik M, Lapidus SK, Bassiri H, et al. American College of Rheumatology Clinical Guidance for multisystem inflammatory syndrome in children associated with SARS-CoV-2 and hyperinflammation in pediatric COVID-19: version 1. Arthritis Rheumatol. 2020;72(11):1791-805.

56. Henderson LA, Canna SW, Friedman KG, Gorelik M, Lapidus SK, Bassiri H, et al. American College of Rheumatology Clinical Guidance for multisystem inflammatory syndrome in children associated with SARS-CoV-2 and hyperinflammation in pediatric COVID-19: version 2. Arthritis Rheumatol. 2021;73(4):e13-29.

57. Schneider J, Tilford B, Safa R, Dentel J, Veenstra M, Ang J, et al. Extracorporeal membrane oxygenation for multisystem inflammatory syndrome in children. Perfusion. 2021:2676591211020904. https://doi.org/10.1177/2676591211020904.

58. McArdle AJ, Vito O, Patel H, Seaby EG, Shah P, Wilson C, et al. Treatment of multisystem inflammatory syndrome in children. $\mathrm{N}$ Engl J Med. 2021 Jul 1:385(1):11-22. An observational cohort study from the BATS Consortium investigating the effects of IVIG alone, corticosteroids alone, and IVIG in combination with corticosteroids on clinical outcomes.

59. Whitworth HB, Sartain SE, Kumar R, Armstrong K, Ballester $\mathrm{L}$, Betensky M, et al. Rate of thrombosis in children and adolescents hospitalized with COVID-19 or MIS-C. Blood. 2021. https://doi.org/10.1182/blood.2020010218.

60. Bansal N, Azeka E, Neunert C, Kim JS, Murray J, May L, et al. Multisystem inflammatory syndrome associated with COVID-19 anti-thrombosis guideline of care for children by action. Pediatr Cardiol. 2021:1-5. https://doi.org/10.1007/s00246-021-02651-9.

61. McCrindle BW, Rowley AH, Newburger JW, Burns JC, Bolger AF, Gewitz M, et al. Diagnosis, treatment, and long-term management of Kawasaki disease: a scientific statement for health professionals from the American Heart Association. Circulation. 2017;135(17):e927-99.

62. Elias MD, McCrindle BW, Larios G, Choueiter NF, Dahdah N, Harahsheh AS, et al. Management of multisystem inflammatory syndrome in children associated with COVID-19: a survey from the International Kawasaki Disease Registry. CJC Open. 2020;2(6):632-40.
63. Dove ML, Jaggi P, Kelleman M, Abuali M, Ang JY, Ballan W, et al. Multisystem inflammatory syndrome in children: survey of protocols for early hospital evaluation and management. J Pediatr. 2021;229:33-40.

64. Buja LM, Wolf DA, Zhao B, Akkanti B, McDonald M, Lelenwa $\mathrm{L}$, et al. The emerging spectrum of cardiopulmonary pathology of the coronavirus disease 2019 (COVID-19): report of 3 autopsies from Houston, Texas, and review of autopsy findings from other United States cities. Cardiovasc Pathol. 2020;48:107233.

65. Halushka MK, Vander Heide RS. Myocarditis is rare in COVID19 autopsies: cardiovascular findings across 277 postmortem examinations. Cardiovasc Pathol. 2021;50:107300.

66. Puntmann VO, Carerj ML, Wieters I, Fahim M, Arendt C, Hoffmann $\mathrm{J}$, et al. Outcomes of cardiovascular magnetic resonance imaging in patients recently recovered from coronavirus disease 2019 (COVID19). JAMA Cardiol. 2020;5(11):1265-73.

67. Kotecha T, Knight DS, Razvi Y, Kumar K, Vimalesvaran K, Thornton G, et al. Patterns of myocardial injury in recovered troponin-positive COVID-19 patients assessed by cardiovascular magnetic resonance. Eur Heart J. 2021;42(19):1866-78.

68. Rajpal S, Tong MS, Borchers J, Zareba KM, Obarski TP, Simonetti $\mathrm{OP}$, et al. Cardiovascular magnetic resonance findings in competitive athletes recovering from COVID-19 infection. JAMA Cardiol. 2021;6(1):116-8.

69. Starekova J, Bluemke DA, Bradham WS, Eckhardt LL, Grist TM, Kusmirek JE, et al. Evaluation for myocarditis in competitive student athletes recovering from coronavirus disease 2019 with cardiac magnetic resonance imaging. JAMA Cardiol. 2021. https://doi.org/10.1001/jamacardio.2020.7444.

70. Shi S, Qin M, Shen B, Cai Y, Liu T, Yang F, et al. Association of cardiac injury with mortality in hospitalized patients with COVID-19 in Wuhan, China. JAMA Cardiol. 2020;5(7):802-10.

71. Guo T, Fan Y, Chen M, Wu X, Zhang L, He T, et al. Cardiovascular implications of fatal outcomes of patients with coronavirus disease 2019 (COVID-19). JAMA Cardiol. 2020;5(7):811-8.

72. Lindner D, Fitzek A, Bräuninger H, Aleshcheva G, Edler C, Meissner K, et al. Association of cardiac infection with SARSCoV-2 in confirmed COVID-19 autopsy cases. JAMA Cardiol. 2020;5(11):1281-5.

73. Imazio M, Klingel K, Kindermann I, Brucato A, De Rosa FG, Adler Y, et al. COVID-19 pandemic and troponin: indirect myocardial injury, myocardial inflammation or myocarditis?. Heart. 2020;106(15):1127-31.

74. Vukomanovic VA, Krasic S, Prijic S, Ninic S, Minic P, Petrovic G, et al. Differences between pediatric acute myocarditis related and unrelated to SARS-CoV-2. Pediatr Infect Dis J. 2021;40(5):e173-8.

75. Ferrero P, Piazza I, Bonino C, Ciuffreda M. Patterns of myocardial involvement in children during COVID-19 pandemic: early experience from northern Italy. Ann Pediatr Cardiol. 2020;13(3):230-3.

76. Clark DE, Parikh A, Dendy JM, Diamond AB, George-Durrett K, Fish FA, et al. COVID-19 myocardial pathology evaluated through screening cardiac magnetic resonance (COMPETE CMR). medRxiv. 2020 Sep 2;2020.08.31.20185140.

77. Marshall M, Ferguson ID, Lewis P, Jaggi P, Gagliardo C, Collins JS, et al. Symptomatic acute myocarditis in seven adolescents following Pfizer-BioNTech COVID-19 vaccination. Pediatrics. 2021. https://doi.org/10.1542/peds.2021-052478.

78. Muthukumar A, Narasimhan M, Li QZ, Mahimainathan L, Hitto I, Fuda F, et al. In depth evaluation of a case of presumed myocarditis following the second dose of COVID-19 mRNA vaccine. Circulation. 2021. https://doi.org/10.1161/CIRCULATIONAHA.121.056038.

79. Eckart RE, Love SS, Atwood JE, Arness MK, Cassimatis DC, Campbell CL, et al. Incidence and follow-up of inflammatory cardiac complications after smallpox vaccination. J Am Coll Cardiol. 2004;44(1):201-5. 
80. Cheng MP, Kozoriz MG, Ahmadi AA, Kelsall J, Paquette K, Onrot JM. Post-vaccination myositis and myocarditis in a previously healthy male. Allergy Asthma Clin Immunol. 2016;12:6.

81. Kim YJ, Bae JI, Ryoo SM, Kim WY. Acute fulminant myocarditis following influenza vaccination requiring extracorporeal membrane oxygenation. Acute Crit Care. 2019;34(2):165-9.
Publisher's Note Springer Nature remains neutral with regard to jurisdictional claims in published maps and institutional affiliations. 